\title{
EFICIÊNCIA DO SISTEMA INTEGRADO DE CRÉDITO AGRÍCOLA MÚTUO*
}

\author{
João Rebelo* \\ Victor Mendes ${ }^{* * *}$
}

Neste trabalho é avaliada a eficiência produtiva anual, perspectivada na óptica do custo, das caixas de crédito agrícola mútuo (CCAM) pertencentes ao sistema integrado de crédito agrícola mútuo (SICAM), através da utilização de uma fronteira custo estocástica.

Para a estimação da eficiência produtiva global, ou eficiência custo, as CCAM são assumidas como empresas multiproduto que comercializam dois produtos, crédito e outras aplicações financeiras, cujo objectivo é a minimização do custo variável, que é igual à soma do dispêndio com a compra de três factores produtivos, depósitos, trabalho e outros materiais.

Os índices de eficiência, calculados com base numa função custo translogarítmica previamente estimada, sugerem que o SICAM pode melhorar a sua "performance" económica se todas as CCAM operarem de forma tão eficiente como as observações de melhor prática. Para um aumento dos níveis de eficiência poderá contribuir uma evolução positiva do rácio activo líquido por trabalhador, do grau de conversão dos depósitos em crédito e da autonomia financeira.

\section{INTRODUÇÃO}

O crédito agrícola mútuo em Portugal tem origem no decreto-lei de 1 de Março de 1911 que criou as Caixas de Crédito Agrícola Mútuo (CCAM). Este

** Universidade de Trás-os-Montes e Alto Douro; Docente Convidado do Instituto Universitário de Desenvolvimento e Promoção Social - Pólo de Viseu da Universidade Católica Portuguesa.

*** Faculdade de Economia do Porto; Docente Convidado do Centro Regional do Porto da Universidade Católica Portuguesa. 
decreto definiu ainda a competência e áreas de intervenção das CCAM, criando em simultâneo a Junta de Crédito Agrícola. Contudo, a actividade das CCAM é extensivamente definida e regulamentada pela lei $n .{ }^{\circ} 215$ de 1914 , bem como pelo decreto n. $^{\circ} 5219$ de 1919.

Até 1920 foram criadas 45 caixas de crédito agrícola, sendo constituídas mais 36 CCAM até 1930. Estas caixas iniciaram a sua actividade num período particularmente difícil, a instabilidade nos anos da $1 .{ }^{a}$ República, a primeira guerra mundial, a crise de Wall Street, a desconfiança em relação à banca, foram características marcantes deste período. Entre 1930 e 1948 foram criadas mais 88 CCAM, embora um número muito significativo delas não tenha entrado em funcionamento.

Até 1976 o sistema de crédito agrícola tinha um peso diminuto no sistema bancário, quer em termos de crédito quer em termos de depósitos, as CCAM nunca chegaram a atingir os $0,75 \%$ da totalidade do sistema. Em 29 de Novembro de 1978 é constituída a FENACAM (Federação Nacional das Caixas de Crédito Agrícola Mútuo), que tinha como objectivo principal o de apoiar e representar as Caixas suas associadas.

A actividade das CCAM tem um crescimento acentuado a partir de 1980, com origem nas possibilidades financeiras proporcionadas pelo regime de crédito à agricultura regulamentado pelo SIFAP (Sistema de Financiamento à Agricultura e Pescas). Neste regime, o recurso a fundos próprios das CCAM para concessão de créditos agrícolas era complementado com a possibilidade de refinanciamentos junto do IFADAP (Instituto Financeiro de Apoio ao Desenvolvimento da Agricultura e Pescas).

O decreto-lei 231/82 de 17 de Junho aprova um novo regime jurídico para o crédito agrícola mútuo, bem como para as cooperativas de crédito agrícola, nele estando prevista a constituição de uma Caixa Central que "terá por objecto principal o financiamento da actividade creditícia das caixas suas associadas, centralizando, para isso, os excessos de liquidez nelas existentes e, em geral, os capitais que a este fim forem afectados" '. No regime adoptado pelo legislador é de salientar a organização territorial do crédito agrícola que se baseia no âmbito concelhio das Caixas Agrícolas ${ }^{2}$. É ainda interessante constatar que apenas os associados de cada Caixa Agrícola podem beneficiar das suas operações activas (crédito), desde que "exerçam na área de acção da caixa agrícola actividades produtivas nos sectores da agricultura, silvicultura e pecuária, e as que exerçam actividades que constituam efectivo complemento, directo e imediato, daquelas actividades" 3 , mas, por outro lado, as caixas agrícolas podem "receber depósitos em moeda nacional dos seus associados ou de terceiros" ${ }^{4}$. O legislador foi ainda bastante restritivo no que respeita à aplicação dos meios líquidos excedentários: "as caixas agrícolas só podem aplicar capitais, não utilizados em operações de crédito agrícola, na constituição de depósitos noutras caixas agrícolas ou na caixa central" ${ }^{5}$. 
Finalmente, refira-se a proibição de distribuição de lucros das caixas agrícolas pelos seus associados, sendo os resultados obrigatoriamente integrados em reservas ${ }^{6}$.

Em 1987 foi criado o Fundo de Garantia, nele participando o Banco de Portugal e a Caixa Central, para além das Caixas de Crédito Agrícola Mútuo. O principal objectivo deste fundo era o de assegurar a solvabilidade do sistema de crédito agrícola.

O SICAM - Sistema Integrado de Crédito Agrícola Mútuo - é criado pelo decreto-lei . $^{\circ}$ 24/91 de 11 de Janeiro. Este diploma consagra também um novo regime jurídico para as CCAM, bem como o alargamento do âmbito das operações de crédito praticadas pelas Caixas Agrícolas. Deste alargamento resultou que as CCAM (bem como a Caixa Central) passaram a poder conceder crédito no âmbito de actividades ligadas à transformação, conservação, transporte e comercialização de produtos, à fabricação e comercialização de factores produtivos, à aquacultura, ao artesanato e ainda à prestação de serviços.

Em finais de 1995 (12 de Setembro), aquele decreto-lei foi actualizado através do decreto-lei n. ${ }^{\circ} 230 / 95$, sendo eliminada a proibição da distribuição de excedentes anuais pelos seus associados e deu-se a possibilidade das reservas darem origem a títulos de capital, igualmente distribuíveis pelos associados. ${ }^{7}$ Foi também consagrado o alargamento do âmbito de intervenção comercial das caixas agrícolas, sendo possibilitado o financiamento das indústrias extractivas.

A 31 de Dezembro de 1995 o SICAM integrava mais de 180 Caixas de Crédito Agrícola Mútuo associadas, que detinham cerca de 500 balcões espalhados pelo território nacional. Cerca de $70 \%$ do crédito concedido ao sector agrícola tinha origem nas CCAM, o que é um sinal evidente do papel que estas instituições têm na sustentabilidade e desenvolvimento do meio rural português.

Neste trabalho ${ }^{8}$ o nosso objectivo é o de estudar a eficiência produtiva das CCAM integradas no SICAM, no período 1990-95. A importância desta análise resulta do acréscimo de concorrência bancária, provocada pela crescente liberalização do mercado bancário, pela alteração das políticas agrícolas em resultado de alterações da PAC, pelo decréscimo de população rural, mais ligada ao sector agrícola, e que poderá afectar a viabilidade das caixas agrícolas em Portugal. A não prossecução de um objectivo de minimização de custos poderá afectar seriamente a sobrevivência destas instituições. Como a área de intervenção de cada caixa se circunscreve ao concelho onde tem a sua sede e aos concelhos limítrofes, desde que neles não exista nenhuma outra caixa em funcionamento, uma CCAM tem dificuldades em aumentar a sua escala de produção, a não ser por fusão, mesmo que existam economias de escala. Consequentemente, poderão resultar elevados índices de ineficiência, comprometendo a sobrevivência da instituição. A estrutura adoptada neste trabalho é a seguinte. Na secção 2 apresentamos a função custo fronteira estocástica inerente ao comportamento das CCAM. 
$\mathrm{Na}$ secção seguinte inserimos os principais resultados. Finalmente, algumas conclusões são apresentadas na secção 4 .

\section{FUNÇÃO CUSTO FRONTEIRA DAS CCAM}

O processo produtivo das CCAM (Mendes e Rebelo, 1996) pode ser expresso pela função custo $C=f(y, w)$ que representa a solução do problema de optimização $\operatorname{Min}\left\{\mathbf{w}^{\prime} \mathbf{x}: \mathbf{y}=\mathrm{g}(\mathbf{x})\right\}$, em que $\mathrm{C}$ representa o custo variável, $\mathbf{x}$ representa o vector de factores variáveis, $\mathbf{w}$ é o vector d' ßrços dos factores variáveis e $\mathbf{y}$ o vector de produtos.

Face ao objectivo de minimização do custo pelas CCAM, a função custo fronteira estocástica inerente ao seu comportamento pode ser expressa por:

(1) $\operatorname{lnC} \mathrm{s}_{\mathrm{s}}=\ln \mathrm{C}(\mathbf{y}, \mathbf{w}, \boldsymbol{\beta})+\mathrm{u}_{\mathrm{s}}+\mathrm{v}_{\mathrm{s}} \quad \operatorname{com} \mathrm{s}=1, \ldots, \mathrm{N}$

em que: $s$ representa a correspondente CCAM; b o vector de parâmetros a estimar; v a componente, bilateral (two-sided), representativa do erro estatístico clássico de média zero e variância homocedástica, $\sigma^{2} ; u$ a componente estocástica unilateral (one-sided) não negativa e cujo valor reflecte a ineficiência custo, sendo esta quantificada em relação à fronteira estocástica [ $1 \mathrm{nC}()+v$.$] .$

Para a estimação dos parâmetros do modelo, os $\mathrm{v}_{\mathrm{s}}$ são assumidos como independentes e identicamente distribuídos (iid), enquanto os $u_{s}$, além de independentes dos $v_{s}$, são considerados como seguindo uma certa distribuição de probabilidade unilateral previamente especificada. Tipicamente, a escolha tem incidido na hipótese de que os $u_{\mathrm{s}}$ estão normalmente semi-distribuídos com média 0 e variân$\operatorname{cia} \sigma_{u}^{2}$.

Uma vez estimados os parâmetros de (1), recorrendo a técnicas de máxima verosimilhança (Greene, 1991), as medidas de ineficiência podem ser calculadas utilizando os resíduos. Para o modelo estocástico normal - seminormal, os índices individuais de ineficiência são estimados através da média condicional de $\mathbf{u}_{\mathrm{s}}$ (Jondrow et al., 1982), com:

2) $\mathrm{E}\left(\mathrm{u}_{\mathrm{s}} \mid \varepsilon_{\mathrm{s}}\right)=\frac{\sigma \mathrm{u} \sigma \mathrm{v}}{\sigma}\left[\frac{\mathrm{f}\left(-\varepsilon_{\mathrm{s}} \lambda / \sigma\right)}{1-\mathrm{F}\left(-\varepsilon_{\mathrm{s}} \lambda / \sigma\right)}+\left(\frac{\varepsilon_{\mathrm{s}} \lambda}{\sigma}\right)\right]$

em que: $\varepsilon_{\mathrm{s}}=\mathrm{u}_{\mathrm{s}}+\mathrm{v}_{\mathrm{s}} ; \sigma^{2}=\sigma_{\mathrm{u}}^{2}+\sigma_{\mathrm{v}}^{2} ; \lambda=\sigma_{\mathrm{u}} / \sigma_{\mathrm{v}} ; \mathrm{f}($.$) e \mathrm{F}($.$) são, respectivamente,$ as funções densidade normal reduzida e distribuição cumulativa normal reduzida.

Na senda de trabalhos recentes neste domínio ${ }^{9}$ consideramos que a actividade bancária é multifacetada, produzindo as CCAM dois produtos distintos (crédito e outras aplicações financeiras) com recurso a três factores de produção (depósitos, trabalho e outros materiais). Admitimos ainda que é objectivo das CCAM a minimização de custos variáveis. 
Neste estudo analisamos o período que decorre de 1990 a 1995. Para a estimação da função custo variável fronteira anual usaram-se as seguintes variáveis:

Produtos:

$\mathrm{y}_{1}=$ saldo de crédito concedido;

$\mathrm{y}_{2}=$ saldo de outras aplicações financeiras.

Factores Produtivos:

$\mathrm{x}_{1}=$ saldo das contas de depósitos;

$\mathrm{x}_{2}=$ número de trabalhadores;

$\mathrm{x}_{3}=$ outros materiais.

Preços dos Factores:

$\mathrm{w}_{1}=$ preço de $\mathrm{x}_{1}$, definido como juros e custos equiparados/saldo dos depósitos totais;

$\mathrm{w}_{2}=$ preço de $\mathrm{x}_{2}$, definido como custos com pessoal/número de trabalhadores;

$\mathrm{w}_{3}=$ preço de $\mathrm{x}_{3}$, definido como (fornecimentos e serviços de terceiros + outros custos)/saldo dos depósitos totais.

$\mathrm{C}$ = custo variável total, definido como a soma de juros e custos equiparados com os custos com o pessoal, fornecimentos e serviços de terceiros e outros custos.

Para a estimação função custo (1) inerente à tecnologia de produção multiproduto das CCAM adoptamos a aproximação translogarítmica de segunda ordem expressa por:

$$
\begin{gathered}
\text { In } C_{s}=\alpha_{0}+\sum_{i=1}^{2} \alpha_{i} \ln y_{i s}+\sum_{i=1}^{3} \beta_{i} \ln w_{i s}+\frac{1}{2} \sum_{i=1}^{2} \sum_{j=1}^{2} \alpha_{i j} \ln y_{i s} \ln j s \\
+\frac{1}{2} \sum_{k=1}^{3} \sum_{j=1}^{3} \delta_{k l} \ln w_{1 s}-\frac{1}{2} \sum_{k=1}^{3} \sum_{i=1}^{2} \mu_{k i} \operatorname{In} w_{k s} \operatorname{In} y_{i s}+u_{s}+v_{s}
\end{gathered}
$$

em que $\mathrm{C}_{\mathrm{s}}=$ custo variável total para a observação $\mathrm{s} ; \mathrm{y}_{\mathrm{is}}=$ produto $\mathrm{i}(\mathrm{i}=1,2)$ para a observação $s ; w_{k s}=$ preço do factor produtivo $k(k=1,2,3)$ para a observação $s$; $\mathrm{s}=1, \ldots, \mathrm{N} ; \mathrm{N}=$ número de observações em cada ano - ver quadro $\mathrm{I}$; símbolos gregos = parâmetros a estimar, comuns a todas as observações em cada ano.

Previamente à estimação dos parâmetros da função (3) e seguindo a metodologia habitual neste tipo de estudos (Rebelo, 1992) foram impostas as restrições de simetria nos parâmetros de segunda ordem e homogeneidade linear nos preços dos factores. A última destas restrições força um dos preços a ser numerário. No nosso caso, quer o custo variável, quer os preços unitários com depósitos e pessoal foram expressos em termos do preço de $x_{3}$.

A informação de base utilizada para a estimação (3) foi recolhida nos balanços e contas de resultados das CCAM para o período 1990-1995. Até 1993 o número de caixas integradas no SICAM era de 209, passando em 1995 para 186, 
redução resultante da fusão de algumas CCAM. A repartição por regiões agrícolas é a contida no quadro I, sendo as regiões da Beira Litoral, Ribatejo e Oeste e Alentejo ${ }^{10}$ as detentoras do maior número de instituições.

\section{Quadro I}

DISTRIBUIÇÃO REGIONAL DAS CAIXAS AGRÍCOLAS "

\begin{tabular}{|l|cccccc|}
\hline Região agrícola & $\mathbf{1 9 9 0}$ & $\mathbf{1 9 9 1}$ & $\mathbf{1 9 9 2}$ & $\mathbf{1 9 9 3}$ & $\mathbf{1 9 9 4}$ & $\mathbf{1 9 9 5}$ \\
\hline Entre Douro e Minho & 33 & 33 & 33 & 35 & 29 & 25 \\
Trás-os-Montes & 24 & 24 & 24 & 24 & 24 & 22 \\
Beira Litoral & 41 & 41 & 41 & 43 & 43 & 43 \\
Beira Interior & 14 & 14 & 14 & 13 & 12 & 12 \\
Ribatejo e Oeste & 37 & 37 & 37 & 37 & 37 & 38 \\
Alentejo & 36 & 36 & 36 & 35 & 33 & 32 \\
Algarve & 17 & 17 & 17 & 16 & 16 & 13 \\
Açores & 7 & 7 & 7 & 1 & 1 & 1 \\
\hline Total Nacional & 209 & 209 & 209 & 204 & 195 & 186 \\
\hline
\end{tabular}

Em 1990 os activos totais do SICAM cifravam-se em cerca de 351 milhões de contos, ultrapassando os 831 milhões em 1995, a que corresponde um valor aproximado por caixa de respectivamente 1,7 e 4,5 milhões de contos (quadro II), representando uma taxa de crescimento média anual nominal de $18,8 \%$.

Quadro II
DADOS SOBRE AS CCAM NO PERÍODO 1990-1995 (A PREÇOS
CORRENTES)

\begin{tabular}{|l|cccccc|}
\hline \multicolumn{1}{|c|}{ Rubricas } & $\mathbf{1 9 9 0}$ & $\mathbf{1 9 9 1}$ & $\mathbf{1 9 9 2}$ & $\mathbf{1 9 9 3}$ & $\mathbf{1 9 9 4}$ & $\mathbf{1 9 9 5}$ \\
\hline Activo líquido por caixa (milhares de contos) & 1677 & 2122 & 2576 & 3149 & 3680 & 4469 \\
Depósitos por caixa (milhares de contos) & 1478 & 2009 & 2435 & 877 & 3431 & 4196 \\
$y_{1}=$ Crédito concedido por caixa (milhares de contos) & 1154 & 1358 & 1537 & 2180 & 1963 & 2206 \\
$y_{2}=$ Outras aplicaçōes por caixa (milhares de contos) & 246 & 300 & 394 & 590 & 1241 & 1764 \\
C= Custo varível por caixa (milhares de contos) & 220 & 292 & 369 & 392 & 376 & 427 \\
$w_{1}=$ Juro médio de depósitos totais (\%) & 12,16 & 12,10 & 12,68 & 11,03 & 8,40 & 7,69 \\
$w_{2}=$ Salário médio (contos) & 1968 & 2423 & 2788 & 2807 & 3408 & 3671 \\
$w_{3}=$ Outros custosisaldo dos depósitos totais (\%) & 1,40 & 1,17 & 1,09 & 1,11 & 1,12 & 1,09 \\
$z_{1}=$ Activo por trabalhador (milhares de contos) & 168 & 199 & 203 & 238 & 254 & 281 \\
$z_{2}=$ Crédito/Depósitos (\%) & 78,06 & $\mathbf{6 7 , 5 8}$ & 63,14 & 75,87 & 57,21 & 52,57 \\
$z_{3}=$ Capital próprio/Activo total (\%) & 6,96 & 6,47 & 5,11 & 2,18 & 1,13 & 0,32 \\
Repartição do custo variável (\%) & & & & & & \\
- Juros e custos equiparados & 79,33 & 80,50 & 80,90 & 78,14 & 74,09 & 73,54 \\
- Custos com pessoal & 10,67 & 10,63 & 11,33 & 12,67 & 14,69 & 14,94 \\
- Fornecimentos e serviços externos+outros custos & 10,00 & 8,82 & 7,77 & 9,19 & 11,22 & 11,52 \\
& & & & & & \\
\hline
\end{tabular}


Exceptuando 1992 e 1993, os depósitos totais, que em 1995 tinham um valor global de 780 milhões de contos (cerca de 4 milhões por caixa), cresceram a taxas anuais superiores às do activo. $O$ crédito concedido cresceu geralmente a taxas inferiores, diminuindo mesmo em 1994, para recuperar ligeiramente em 1995, ano em que o valor total do crédito concedido atinge os $\mathbf{4 3 2}$ milhões de contos. Face às dificuldades de concessão de crédito, as caixas incrementaram a rubrica "outras aplicações", que passou de 51 para 328 milhões de contos entre 1990 e 1995, representando um crescimento médio anual de $45 \%$. Estes movimentos diferenciados traduziram-se numa evolução desfavorável do rácio de conversão dos depósitos em créditos, que passou de 78\% em 1990 para 53\% em 1995.

As dificuldades na concessão de crédito ao sector agrícola originaram uma contínua degradação dos resultados das CCAM. O SICAM tem conhecido resultados negativos desde 1992, que não têm sido compensados por outras rubricas da situação líquida. Em 1990 os capitais próprios representavam 7\% do activo total, enquanto em 1995 este valor era apenas de $0,32 \%$. Uma explicação parcial para este comportamento está na evolução da margem financeira (diferença entre juros recebidos e pagos por unidade de activo), a qual passou de 4,62\% em 1990 para 3,13\% em 1995, assistindo-se a uma certa incapacidade de redução dos custos operativos capaz de acompanhar a redução da taxa de juro do crédito. Isto apesar do decréscimo da taxa de juro média dos depósitos, em especial nos anos de 1994 e 1995. Os custos com pessoal por trabalhador cresceram a uma taxa média anual de 13,3\%, sendo o activo por trabalhador de 168 e 281 milhares de contos em 1990 e 1995, respectivamente. Em relação ao valor dos depósitos, o peso relativo de outros custos diminuiu ligeiramente, de 1,4\% em 1990 para 1,1\% em 1995.

A crescente concorrência na actividade bancária, com a inerente redução da margem de intermediação financeira, obriga as CCAM a um maior dinamismo e a uma redução de custos, isto é, a imporem que elas tentem ser produtivamente eficientes na utilização dos recursos produtivos ao seu dispor.

\section{RESULTADOS}

O índice de eficiência produtiva anual de cada CCAM foi calculado recorrendo à expressão (2). Os parâmetros dos seis modelos fronteira, um para cada ano da amostra, foram estimados através de (3). No quadro III constam as estimativas dos parâmetros das funções custo fronteira. 
Quadro III

PARÂMETROS DAS FUNÇÕES CUSTO FRONTEIRA

\begin{tabular}{|c|c|c|c|c|c|c|}
\hline Variável & 1990 & 1991 & 1992 & 1993 & 1994 & 1995 \\
\hline $\begin{array}{l}\text { Constante } \\
\ln y_{1} \\
\ln y_{2} \\
\ln w_{1} \\
\ln w_{2} \\
\ln y_{1} \ln y_{1} \\
\ln y_{1} \ln y_{2} \\
\ln y_{2} \ln y_{2} \\
\ln w_{1} \ln w_{1} \\
\ln w_{1} \ln w_{2} \\
\ln w_{2} \ln w_{2} \\
\ln y_{1} \ln w_{1} \\
\ln y_{1} \ln w_{2} \\
\ln y_{2} \ln w_{1} \\
\ln y_{2} \ln w_{2}\end{array}$ & $\begin{array}{c}5,425^{*} \\
0,079 \\
0,053^{*} \\
-0,299^{*} \\
1,224^{*} \\
0,059^{*} \\
-0,014^{*} \\
0,020^{*} \\
-0,179 \\
0,469^{*} \\
-0,524^{*} \\
-0,070 \\
0,033 \\
-0,005 \\
0,013^{*}\end{array}$ & $\begin{array}{c}5,931^{*} \\
1,717^{*} \\
0,085 \\
1,066 \\
0,212 \\
0,501^{*} \\
-0,010^{*} \\
-0,021^{*} \\
0,196 \\
-0,127 \\
0,165 \\
0,056 \\
-0,133^{*} \\
0,005 \\
-0,003\end{array}$ & $\begin{array}{c}10,97^{* *} \\
0,667 \\
0,156^{* *} \\
3,971^{* *} \\
-1,985 \\
0,039^{*} \\
-0,013^{*} \\
0,024^{*} \\
0,579 \\
-0,175 \\
0,194 \\
-0,179^{*} \\
0,012 \\
0,008 \\
-0,008\end{array}$ & $\begin{array}{c}6,245 \\
0,146 \\
0,366^{*} \\
1,208 \\
0,501 \\
0,071^{*} \\
-0,026^{*} \\
0,037^{*} \\
0,498 \\
-0,056 \\
-0,039 \\
-0,116^{*} \\
0,040 \\
0,015 \\
-0,020^{* *}\end{array}$ & $\begin{array}{l}1,854 \\
0,861^{*} \\
0,009 \\
1,757^{* *} \\
-0,206 \\
0,135^{*} \\
-0,116^{*} \\
0,118^{*} \\
0,799^{*} \\
-0,294 \\
0,121 \\
0,041 \\
-0,095 \\
-0,167^{* *} \\
0,124\end{array}$ & $\begin{array}{c}22,662 \\
1.557^{* *} \\
-2,176^{*} \\
7.5())^{*} \\
-2,245 \\
0,118^{*} \\
-0,079^{*} \\
0,094^{*} \\
0,624 \\
-0,505^{* *} \\
0,193 \\
-0,128 \\
-0,083 \\
-0,067 \\
0,204^{*}\end{array}$ \\
\hline
\end{tabular}

* Parâmetro significativo a 5\%; ** Parâmetro significativo a $10 \%$

De acordo com os valores contidos no quadro IV, na média geométrica, as proporções (shares) referentes a custos com depósitos, trabalho e outros materiais são positivas e inferiores à unidade, indicando que, anualmente, alterações relativas nos preços dos factores originam modificações relativas no mesmo sentido no custo variável. Comparando os valores observados (quadro II) das equações proporção com os das estimadas verficamos que, dentro de um comportamento optmizador das CCAM, o peso relativo dos juros e custos equiparados, e dos encargos com pessoal no custo variável deveriam, respectivamente, aumentar e diminuir. Por exemplo, em 1995, estes movimentos seriam de $+11,98 \%$ $(85,52 \%-73,54 \%)$ para os juros e de $-7,95 \%(6,99 \%-14,94 \%)$ para o trabalho. Para os restantes encargos administrativos (fornecimento e serviços externos + outros custos) a tendência é para a diminuição do seu peso relativo nos custos variáveis, sendo a respectiva proporção estimada de $16,7 \%$ em 1990 e de $7,5 \%$ em 1995. 


\section{Quadro IV \\ PROPORÇÕES ESTIMADAS E ELASTICIDADES CUSTO, NA MÉDIA GEOMÉTRICA}

\begin{tabular}{|l|rrrrrr|}
\hline & 1990 & 1991 & 1992 & 1993 & 1994 & 1995 \\
\hline Proporções estimadas (\%) & & & & & & \\
- Juros e custos equiparados & 64,98 & 77,25 & 80,68 & 82,85 & 83,50 & 85,52 \\
- Custos com pessoal & 18,28 & 7,99 & 7,97 & 8,13 & 5,32 & 6,99 \\
- Fornecimentos s. externos + outros custos & 16,74 & 14,76 & 11,35 & 9,02 & 11,18 & 7,49 \\
Elasticidade custo de crédito concedido $\left(y_{1}\right)$ & 0,774 & 0,826 & 0,797 & 0,785 & 0,605 & 0,570 \\
Elasticidade custo de outras aplicações $\left(y_{2}\right)$ & 0,078 & 0,085 & 0,117 & 0,121 & 0,336 & 0,364 \\
Elasticidade custo total & 0,852 & 0,911 & 0,914 & 0,906 & 0,941 & 0,934 \\
Economias de escala globais (EEG) & 1,174 & 1,098 & 1,094 & 1,104 & 1,063 & 1,071 \\
& & & & & &
\end{tabular}

As elasticidades custo-produto estimadas são igualmente positivas e inferiores à unidade, indicando que uma variação de $1 \% \mathrm{em}$ cada um dos produtos (crédito concedido e outras aplicações), mantendo tudo o resto constante, provoca alterações no mesmo sentido, embora menos que proporcionais, no custo variável. $\mathrm{O}$ valor da elasticidade custo do crédito concedido diminuiu, passando de 0,77 em 1990 para 0,57 em 1995, enquanto, no mesmo período, o referente a outras aplicações subiu de 0,078 para 0,364 . Os resultados obtidos para as economias de escala globais (EEG), inverso da soma das elasticidade custo de cada um dos produtos, indicam que no período 1990-95 não houve uma alteração relevante na estratégia das CCAM capaz de as conduzir a uma modificação no comportamento dos custos, operando sempre numa situação de rendimentos crescentes à escala ${ }^{11}$. Indicam, também, que o aumento da competitividade das CCAM pode ser conseguido através de um aumento de dimensão, ou seja, através de uma expansão simultânea do crédito concedido e de outras aplicações financeiras.

Na função custo translogarítmica, a ineficiência custo implica que o custo observado seja superior ao custo mínimo (fronteira estocástica estimada) em $\left.\exp \left(u_{s} \mid \varepsilon_{s}\right)\right]$, sendo o índice de eficiência custo (custo mínimo/custo observado) ou eficiência produtiva global $(E P G)$ dado por $\left.E P G=1 / \exp \left(u_{s} \mid \varepsilon_{s}\right)\right]$.

No quadro $\mathrm{V}$ incluímos dados estatísticos sobre os índices estocásticos de EPG. O coeficiente de variação localiza-se entre $7,3 \%$ e $11,8 \%$, sendo a variabilidade dos índices de EPG muito semelhante nos anos de 1990, 1994 e 1995. Atinge o valor mais elevado em 1991 e o mais baixo em 1993. Em todos os anos a mediana é superior à média, ou seja a maioria das CCAM têm um índice de eficiência superior ao valor médio do conjunto das observações. 


\section{Quadro V}

DADOS ESTATÍSTICOS SOBRE OS ÍNDICES DE EPG

\begin{tabular}{|l|cccccc|}
\hline & 1990 & 1991 & 1992 & 1993 & 1994 & 1995 \\
\hline Mínimo & 0,513 & 0,462 & 0,531 & 0,607 & 0,431 & 0,501 \\
Máximo & 0,984 & 0,988 & 0,972 & 0,977 & 0,981 & 0,979 \\
Média & 0,861 & 0,850 & 0,863 & 0,888 & 0,864 & 0,873 \\
Mediana & 0,888 & 0,873 & 0,882 & 0,909 & 0,887 & 0,891 \\
C.Variação (\%) & 10,6 & 11,8 & 9,4 & 7,3 & 10,5 & 10,2 \\
\hline
\end{tabular}

No período 1990-1995, caso todas as caixas tivessem adoptado o comportamento económico, em termos técnicos e de afectação de recursos, das observações de "melhor prática", a redução nos custos operativos seria sucessivamente de $13,9 \%, 15 \%, 13,7 \%, 11,2 \%, 13,6 \%$ e $12,7 \%$, que em valor se traduziria numa poupança, com os consequentes acréscimos nos resultados da exploração, de aproximadamente $6,9,11,10,10$ e 10 milhões de contos, repectivamente, para cada um dos anos.

Os resultados obtidos neste trabalho são consistentes com os conseguidos em anterior estudo (Mendes e Rebelo, 1996), em que se calcularam os índices deterministas de eficiência, isto é, quantificados em relação a uma fronteira custo não paramétrica estimada através de programação linear. Satisfazendo o previsto na teoria, o que nem sempre acontece (Ferrier e Lovell, 1990), os índices deterministas de eficiência são genericamente inferiores aos estocásticos. Nos primeiros os acontecimentos aleatórios são assumidos como ineficiência, o que já não acontece nos índices estocásticos. Com excepção de $1992^{12}$, ano em que o coeficiente de correlação é estatisticamente não significativo, os coeficientes de correlação indicam que existe uma relação linear positiva entre os indicadores derivados por ambos os métodos. Ambas as metodologias indicam que a maioria das CCAM podia melhorar a sua "performance" para o volume e gama de produtos comercializados.

Numa tentativa de detectarmos ligações entre a eficiência custo e certos indicadores económico-financeiros caracterizadores da actividade das CCAM estimámos, para cada ano, a regressão linear:

(4) $\quad E P G=a_{0}+a_{1} Z_{1}+a_{2} Z_{2}+a_{3} Z_{3}+e$ em que: $a_{i}(i=0,1,2,3)$ são os parâmetros a estimar; $Z_{1}=$ activo líquido por trabalhador; $Z_{2}=$ crédito/depósitos; $Z_{3}=$ capital próprio/activo líquido total; $\mathrm{e}=$ erro estatístico.

Os valores obtidos (quadro VI) sugerem que o activo líquido por trabalhador, ou produtividade, apenas se tornou relevante para o comportamento da eficiência 72 produtiva a partir de 1994. Para este evento não deve ser alheio o peso dos encar- 
gos com pessoal no custo variável, cuja proporção passou de 10,7\% em 1990 para 14,9\% em 1995. A partir de 1991, exceptuando 1995 para $Z_{2}$, os coeficientes parciais da regressão associados às variáveis $Z_{2}$ e $Z_{3}$ são positivos e estatisticamente significativos, indicando que as CCAM podem aumentar o seu nível de eficiência produtiva através da evolução positiva do grau de conversão dos depósitos em crédito e de uma redução do nível de endividamento, através do reforço dos capitais próprios.

\section{Quadro VI}

PARÂMETROS DAS REGRESSÕES DA EPG

\begin{tabular}{|l|clllll|}
\hline \multicolumn{1}{|c|}{ Variáveis } & 1990 & 1991 & 1992 & 1993 & 1994 & 1995 \\
\hline Constante & $0,8554^{*}$ & $0,6396^{*}$ & $0,7138^{*}$ & $0,7990^{*}$ & $0,7953^{*}$ & $0,8297^{*}$ \\
$Z_{1}$ & 0,0004 & 0,0000 & 0,0000 & 0,0000 & $0,0000^{*}$ & $0,0000^{*}$ \\
$Z_{2}$ & 0,0004 & $0,2902^{*}$ & $0,2158^{*}$ & $0,1130^{*}$ & $0,8779^{*}$ & 0,0360 \\
$Z_{3}$ & $-0,0013$ & $0,3891^{*}$ & $0,2825^{*}$ & $0,2996^{*}$ & $0,4215^{*}$ & $0,0360^{*}$ \\
$R^{2}(\%)$ & 25,6 & 32,1 & 28,3 & 53,1 & 68,9 & 67,5 \\
\hline
\end{tabular}

* Parâmetros significativos a 5\%.

Os resultados anteriores foram derivados tendo por base a função custo anual (3) previamente estimada. Para avaliarmos a rebustez e permanência dos resultados ao longo de todo o período considerado, estimámos a seguinte função custo fronteira alternativa:

(5) $\quad \ln C_{\mathrm{s}}=\operatorname{lnC}(\mathbf{y}, \mathbf{w}, \mathbf{t}, \beta)+\mathrm{u}_{\mathrm{s}}+\mathrm{v}_{\mathrm{s}} \quad \operatorname{com} \mathrm{s}=1, \ldots, \mathrm{N}$

sendo $t$ a variável tempo representativa do trend temporal que vai de 1990 a $1995(t=1, \ldots, 6)$, tendo as restantes variáveis e parâmetros o mesmo significado que na função custo fronteira (3). A variável $t$, que capta eventuais alterações tecnológicas, foi introduzida no modelo do mesmo modo que as variáveis y e w.

O modelo foi estimado a partir de uma pooling de 1212 observações, sendo todos os dados reconvertidos a preços constantes de 1990, utilizando-se o deflator do produto interno bruto (PIB).

Os valores obtidos para os indicadores de eficiência produtiva global (EPG), de economias de escala globais (EEG) e parâmetros da regressão da EPG (quadro VII), confirmam os derivados a partir das funções custo anuais, ainda que em termos absolutos com algumas diferenças. A EPG varia entre 0,829 e 0,872 e as EEG são sempre superiores à unidade, ou seja, as CCAM operam, permanentemente, numa situação de economias de escala. Os parâmetros associados às variáveis $Z_{1}, Z_{2}$ e $Z_{3}$, além de estatisticamente significativos, são positivos, reafirmando a ideia de que as CCAM podem aumentar a sua eficiência produtiva 
através de melhorias na produtividade aparente do trabalho (activo por trabalhador), conversão dos depósitos em crédito e autonomia financeira.

\section{Quadro VII \\ EFICIÊNCIA PRODUTIVA GLOBAL (EPG) E ECONOMIAS DE ESCALA GLOBAIS (EEG) PARA O MODELO POOLING}

\begin{tabular}{|l|cllllll|}
\hline & Total & 1990 & 1991 & 1992 & 1993 & 1994 & 1995 \\
\hline Eficiência produtiva global (EPG) & & & & & & & \\
$\cdot$ & 0,851 & 0,861 & 0,867 & 0,829 & 0,872 & 0,839 & 0,836 \\
Média & 7,76 & 4,99 & 5,51 & 6,76 & 5,50 & 11,44 & 9,57 \\
Economias de escala globais (EEG) & 1,321 & 1,294 & 1,244 & 1,299 & 1,294 & 1,460 & 1,370 \\
Número de observações & 1212 & 209 & 209 & 209 & 204 & 195 & 186 \\
Parâmetros da regressão da EPG & & & & & & & \\
$\cdot$ Constante & $0,693^{*}$ & & & & & & \\
$\cdot \mathrm{Z}_{1}$ & $0,000^{*}$ & & & & & & \\
$\cdot \mathrm{Z}_{2}$ & $0,179^{*}$ & & & & & & \\
$\cdot \mathrm{Z}_{3}$ & $0,236^{*}$ & & & & & & \\
$\cdot \mathrm{R}^{2}(\%)$ & 50,9 & & & & & & \\
\hline
\end{tabular}

* Parâmetro significativo a 5\%.

\section{CONCLUSÕES}

Neste trabalho procurámos analisar as condições de produção das caixas de crédito agrícola mútuo integradas no sistema de crédito agrícola mútuo em Portugal, durante a primeira metade da década de noventa. A eficiência produtiva anual, perspectivada na óptica do custo, foi calculada em relação a uma função custo estocástica, sendo os parâmetros estimados pelo método da máxima-verosimilhança. Assim, os índices de eficiência calculados estão expurgados de factores incontroláveis pelos gestores das CCAM, como, por exemplo, falhas e imperfeições de mercado.

Os índices de eficiência sugerem que a maioria das CCAM tem níveis de eficiência superior à média, e que, no período observado, caso todas as caixas de crédito agrícola adoptassem a tecnologia das de melhor prática, a redução anual dos custos operativos estaria situada entre os $11,2 \%$ de 1993 e os $15 \%$ de 1991 , a que corresponde, para o conjunto do SICAM, uma poupança média anual de custos na ordem dos 9 milhões de contos.

Os gestores das CCAM não optimizam o aproveitamento dos recursos disponíveis, tendo futuramente de adoptar estratégias capazes de melhorar a "perfor- 
mance" produtiva das caixas. No curto prazo, a ineficiência produtiva conduz a uma diminuição da rendibilidade e, no longo prazo, coloca em causa a competitividade das empresas. As CCAM integradas no SICAM podem reduzir o grau de ineficiência se elevarem a produtividade do trabalho, o grau de conversão dos depósitos em crédito e, ainda, a sua autonomia financeira. Contudo, alguns destes objectivos poderão estar prejudicados pelas condições normativas de enquadramento das actividades legalmente permitidas às CCAM.

\section{NOTAS}

* Trabalho inserido no projecto de investigação "Sistema Financeiro, Eficiência e Crescimento Económico", financiado pela JNICT (Proj. PCSH/ECO/938/95).

1 Art. ${ }^{\circ} 55$, n. $^{\circ} 1$ do anexo ao DL 231/82 de 17 de Junho. A 20 de Junho de 1984 era criada a Caixa Central de Crédito Agrícola Mútuo.

2 Art. $^{\circ} 8 .^{\circ}$ do anexo ao DL n. ${ }^{\circ} 231 / 82$ de 17 de Junho. A área de intervenção de cada caixa circunscreve-se ao concelho onde tiver a sua sede e aos concelhos limìtrofes, desde que neles não exista nenhuma outra em funcionamento.

3 Art. ${ }^{\circ} 12 .^{\circ}$, n. $^{\circ} 1$, e art. ${ }^{\circ} 32$ n. ${ }^{\circ} 1$ do anexo ao DL n. ${ }^{\circ} 231 / 82$ de 17 de Junho,

4 Art. $17 .^{\circ}$, alínea $a$ ), do anexo ao DL $\mathrm{n}^{\circ} 231 / 82$ de 17 de Junho.

5 Art. ${ }^{\circ} 31 .^{\circ}$ do anexo ao DL n. ${ }^{\circ} 231 / 82$ de 17 de Junho.

6 Art. $^{\circ} 45 .^{\circ}$ do anexo ao DL n. ${ }^{\circ} 231 / 82$ de 17 de Junho.

7 Art. $^{\circ} 43 .^{\circ}$ do DL n. ${ }^{\circ} 230 / 95$ de 12 de Setembro.

8 Em trabalho anteriormente realizado por Mendes e Rebelo (1996), analisaram-se as economias de escala e de gama do SICAM, a partir de uma função custo "média", e ainda a eficiência produtiva calculada pelo método de programação não paramétrico.

9 Ver, por exemplo, Noulas et al (1990), Hunter et al (1989), Pinho (1994), Mendes (1995) e Canhoto (1996).

10 Em Rebelo e Mendes (1996) encontra-se uma análise da situação económico-financeira das CCAM por região agrícola.

11 Os valores das EEG calculados a partir dos parâmetros fronteira são muito idênticos aos calculados em trabalho anterior (Mendes e Rebelo, 1996), em que se partiu da função custo "média" estimada pela técnica SURE.

12 Para o período 1990-1995, os coeficientes de correlação linear entre a EPG estocástica e a EPG determinista são sucessivamente 0,$49 ; 0,40 ;-0,022 ; 0,53 ; 0,68 ; 0,55$. 


\section{REFERÊNCIAS BIBLIOGRÁFICAS}

CANHOTO, A. (1996), "Technical Efficiency in the Portuguese Banking Sector: A Non-Parametric Approach", Universidade Católica Portuguesa, Lisboa, working paper \#71, 96, Março.

FERRIER, G. D. e LOVELL, C. A. K. (1990), "Measuring Cost Efficiency in Banking: Econometric and Linear Programming Evidence", Journal of Econometrics, 46, pp. 229-245.

GREENE, H. William (1991), LIMDEP, Version 6.0, User's Manual and Reference Guide. Econometric Software, Inc., New York, pp. 661-680.

HUNTER, W. C.; TIMME, S. G. e YANG, W. K. (1989), “An Examination of Cost Subadditivity and Multiproduct Production in Large U. S. Banks". Federal Reserv Bank of Atlanta Working Paper \#89-3.

JONDROW, J.; LOVELL, C. A. K.; MATEROV, I. S. e SCHMIDT, P. (1982), "On the Estimation of Technical Inefficiency in the Stochastic Frontier Production Function Model", Journal of Econometrics, 19, pp. 233-238.

MENDES, Victor (1995), "Productive Efficiency in Portuguese Banking: The Years 1990-92", in Business Research Yearbook-Global Business Perspectives, Abbas F. Alkhafaji ed., Vol. II, pp. 400-404.

MENDES, Victor e REBELO, João (1996), "Relações Custo-Produção e Eficiência Produtiva no sistema Integrado de Crédito Agrícola Mútuo: Estudo dos Anos 1990-1995". Comunicação apresentada no $5 .^{\circ}$ Encontro Nacional de Economia Industrial, Coimbra, Setembro, $31 \mathrm{p}$.

NOULAS, A. G.; RAY, S. C. e MILLER, S. M. (1990), "Returns to Scale and Input Substitution for Large U. S. Banks", Journal of Money, Credit and Banking, Vol. 12 \#1, pp. 94-107.

PINHO, P. (1994), Essays on Banking. PhD dissertation, City University Business School.

REBELO, João (1992), Análise de Relaçães Custo-Produção e Eficiência Produtiva em Empresas Multiproduto: O Caso das Adegas Cooperativas da Região Demarcada do Douro, UTAD, Vila Real.

REBELO, João e MENDES, Victor (1996), "As Caixas de Crédito Agrícola Mútuo na primeira metade dos anos noventa", Economia e Sociologia, n. ${ }^{\circ}$ 62, Évora, pp. 93-109. 